\title{
Kentucky Bluegrass and Perennial Ryegrass Mixtures for Establishing Midwest Lawns
}

\author{
Christopher A. Proctor \\ Department of Agronomy and Horticulture, University of Nebraska-Lincoln, \\ 161 Keim Hall, Lincoln, NE 68583
}

\author{
Daniel V. Weisenberger \\ Department of Agronomy, Purdue University, 915 W. State Street, West \\ Lafayette, IN 47907-2054
}

Zachary J. Reicher ${ }^{1}$

Department of Agronomy and Horticulture, University of Nebraska-Lincoln, 161 Keim Hall, Lincoln, NE 68583

Additional index words. turfgrass establishment, seeding mixtures, chlorsulfuron

\begin{abstract}
Mixtures of turfgrass seed are commonly used to establish lawns, with kentucky bluegrass (KBG) and perennial ryegrass (PRG) comprising two of the more commonly used species. In the humid regions of the Midwest United States, KBG is a desirable species, but slow germination makes it difficult to establish compared with PRG. The objective of our study was to evaluate establishment rate and species composition over 3 years of a turf stand seeded with different ratios of KBG and PRG (wt:wt) maintained as a lawn. Repeat experiments were initiated in 2007 and 2008 and conducted for 3 years in West Lafayette, IN, with seed mixtures of KBG:PRG of 100:0, 90:10, 80:20, 70:30, 50:50, and 0:100 wt:wt of pure live seed. Plots were seeded late August each year and percent turfgrass cover was rated up to 6 weeks after seeding (WAS). To evaluate stand composition after establishment, percent KBG cover was rated annually in August for 3 years using transect counts after selective removal of PRG with the herbicide chlorsulfuron. Likely as a result of greater crabgrass (Digiaria sp.) competition during establishment in 2007, 100\% PRG, 50:50, 70:30, or 80:20 KBG:PRG ratio had the highest percentage turf cover at 6 WAS, whereas there was no difference between treatments at 6 WAS in 2008 when crabgrass competition was lower. Regardless of turf cover during establishment, all treatments except $100 \%$ PRG shifted to greater than $95 \%$ KBG cover by 3 years after establishment. For the region in which our study was conducted, it may be desirable to seed with a higher proportion (greater than $50 \%$ ) of PRG to speed initial establishment for customer satisfaction, erosion control, and/or to offset years with high weed pressure. Under lawn conditions similar to our study, seeding ratios with high KBG (80:20 or 90:10 KBG:PRG) will likely shift to a stand composition of greater than $95 \%$ KBG within 2 years, whereas all other ratios lower in KBG will likely shift similarly within 3 years. Chemical names used: 2 -chloro-N-\{[(4-methoxy-6methyl-1,3,5-triazin-2 yl)amino]carbonyl \}benzenesulfonamide (chlorsulfuron)
\end{abstract}

Kentucky bluegrass (Poa pratensis L.) mixed with PRG (Lolium perenne L.) is a common seed mixture for lawn establishment. Seed mixes capitalize on the beneficial aspects of each turfgrass species such as differences in disease/insect resistance, water use efficiency, and/or traffic tolerance (Brede and Duich, 1984a; Davis, 1958; Dunn et al., 2002; Gibeault et al., 1980). The primary advantage of PRG is rapid germination and establishment (Blaser et al., 1956), providing turf cover to compete with weeds and maximize customer satisfaction when establishing a lawn. However, PRG is susceptible to numerous diseases in the humid regions of

Received for publication 6 Aug. 2014. Accepted for publication 18 Nov. 2014

${ }^{1}$ To whom reprint requests should be addressed; e-mail zreicher2@unl.edu. the Midwest United States and stands often thin in the heat and humidity of late summer or in winter from desiccation or extended snow cover without aggressive maintenance. Although KBG is slow to germinate and establish, it is desirable in the long term because it spreads by rhizomes, is relatively droughttolerant, and will accommodate a wide range of management systems.

Ideally, a turf stand would be composed of equal amounts of KBG and PRG (Gibeault et al., 1980). This can be challenging in the short term because PRG germinates in 3 to $10 \mathrm{~d}$ and can outcompete KBG, which takes up to $28 \mathrm{~d}$ to germinate (Christians, 2011). Furthermore, monostands of PRG have almost twice the seedling survival as KBG (Brede and Duich, 1984a). Brede (1982) also suggests the presence of PRG may further reduce $\mathrm{KBG}$ seedling survival as a result of allelopathic effects. To compensate for PRG's competitive advantage during germination, suggested seed mixtures comprise between $50 \%$ and $95 \%$ KBG by weight (Brede and Duich, 1984a; Gibeault et al., 1980; Larsen et al., 2004; Larsen and Bibby, 2005), which is between $80 \%$ and $98 \%$ KBG by seed number. In addition to the seeding ratio of PGR and $\mathrm{KBG}$, several other factors may affect shortterm composition of the turf stand. Date of planting and simulated sports turf traffic (Stier et al., 2008), cultivar selection (Brede, 1982), and time to initial mowing and mowing height (Brede and Duich, 1984b) have been shown to influence the short-term composition of a stand seeded with a mixture of KBG and PRG.

Furthermore, stand composition is likely dynamic as a result of the environment, pests, and/or management, and thus considerable variation is reported for the long-term composition of turf stands originally seeded as a mixture of KBG and PRG. Brede (1982) reports KBG eventually dominated a turf stand that was initially dominated by PRG in Pennsylvania. In later work by Brede (2005) in Idaho, KBG consisted of $50 \%$ to $97 \%$ of the stand 5 years after seeding 50:50 KBG:PRG (wt:wt) depending on the KBG cultivar used in the seed mixture. Conversely in Missouri, Dunn et al. (2002) reported PRG as the dominant species under simulated traffic after 5 years with initial seed ratios of KBG:PRG of 80:20 (wt:wt) regardless of irrigation regime or mowing at 1.9 or $5.1 \mathrm{~cm}$. Hsiang et al. (1997) reported PRG as the dominant species after 4 years with initial seed ratios of KBG:PRG at 50:50 (wt:wt) in a study in Ontario, Canada, when mowed at $3.5 \mathrm{~cm}$ and irrigated to prevent drought stress.

Landscape contractors are pressured to deliver lawns from seed quickly for customer satisfaction. Therefore, lawn seed mixes including PRG at $50 \%$ or more by weight are readily available at wholesale and retail outlets. Perceived cost savings from use of PRG over KBG may also influence seed mixture composition. However, few studies have evaluated how initial composition of KBG:PRG in the seed mixture affects species composition over multiple years in the humid Midwest, just north of the transition zone of adaptability between cool- and warm-season turfgrasses Our objective was to evaluate the establishment and species composition after 3 years of a turf stand seeded with different ratios of KBG and PRG and maintained as a lawn.

\section{Materials and Methods}

Duplicate experiments were seeded adjacently on 15 Aug. 2007 and 26 Aug. 2008 at Purdue University's W.H. Daniel Turfgrass Research and Diagnostic Center in West Lafayette, IN, and data were collected for 4 or 3 years, respectively. Soil was a Chalmers silt loam (fine silty mixed mesic Typic Haplaquoll) with $220 \mathrm{~kg}$ phosphorus (P)/ha, $600 \mathrm{~kg}$ potassium/ha, $\mathrm{pH} 7.2$, and $3.8 \%$ organic matter. The areas were fallow for at least 1 year before each experiment was initiated. Before seeding, areas were tilled to a depth of $10 \mathrm{~cm}$, smoothed with a drag mat, and hand-raked to 
prepare the seedbed. Experiments were seeded by a handheld shaker jar with various ratios of a KBG blend consisting of $20 \%$ each of 'Odyssey', 'Arcadia', 'Mercury', 'SR2100', and 'America' or a perennial ryegrass blend consisting of 33\% each of 'SR4600', 'Penguin', and 'Fiesta 3'. These blends were commercially available and no attempt was made to select and/or differentiate specific cultivars. Seed ratios of KBG:PRG (wt:wt) were 100:0, 90:10, 80:20, 70:30, 50:50, or 0:100 (Table 1), and the target seed rate was 1.9 pure live seeds $/ \mathrm{cm}^{2}$ as proposed by Brede and Duich (1984a) based on an average of 4795 KBG seeds/g and 500 PRG seeds/g (Beard, 1973). Plots were $3 \mathrm{~m} \times 3 \mathrm{~m}$ with $0.5 \mathrm{~m}$ PRG borders on all sides. The area was covered with a germination blanket (AgroFabric Pro17; American Agrifabrics, Alpharetta, GA) to prevent seed from washing into adjacent plots and irrigated as needed to encourage germination. Starter fertilizer $(6 \mathrm{~N}-10.5 \mathrm{P}-20 \mathrm{~K})$ was applied at $25.5 \mathrm{~kg} \mathrm{P} / \mathrm{ha}$ at seeding and again in mid-September, followed by urea $(46 \mathrm{~N}-0 \mathrm{P}-0 \mathrm{~K})$ at $49 \mathrm{~kg}$ nitrogen $(\mathrm{N}) / \mathrm{ha}$ in November. Annual maintenance included mowing at $6.4 \mathrm{~cm}$ height twice per week with clippings returned, irrigation to prevent drought stress, and $170 \mathrm{~kg} \mathrm{~N} /$ ha/year with $49 \mathrm{~kg} \mathrm{~N} / \mathrm{ha}$ applied in September and early November and $36 \mathrm{~kg} \mathrm{~N} / \mathrm{ha}$ applied in late May and early July. Crabgrass (Digitaria spp.) was controlled with dithiopyr [S,S-dimethyl 2-(difluoromethyl)-4-(2-methylpropyl)-6(trifluoromethyl)-3,5-pyridinedicarbothioate] applied in April of each year, three-way phenoxy herbicide (2,4-D + dicamba+ MCPP) $[(2,4$-dichlorophenoxy)acetic acid $+3,6-$ dichloro-2-methoxybenzoic acid +(6)-2-(4chloro-2-methylphenoxy)propanoic acid] was applied in September beginning the second year after establishment to control minimal (less than 1\% cover) infestation of dandelions (Taraxacum officinale), and white grubs were controlled with preventive applications of imidacloprid \{2-chloro-N-[((4-methoxy-6methyl-1,3,5-triazin-2-yl)amino)carbonyl] benzenesulfonamide $\}$ in July of each year, which are all typical lawn maintenance practices in Indiana.

Turfgrass cover was visually estimated at 2, 3, 4, and 6 WAS beginning 30 Aug. 2007 and at 3, 4, 5, and 6 WAS beginning 5 Sept. 2008 . Weed cover was visually estimated on 15 Oct. 2007 and 14 Oct. 2008. Kentucky bluegrass cover was determined annually for 4 (2007-initiated study) or 3 years (2008-initiated study) after selective removal of PRG from one-quarter of each plot with $0.5 \mathrm{~kg} \cdot \mathrm{ha}^{-1}$ chlorsulfuron \{2-chloro-N-[((4-methoxy-6methyl-1,3,5-triazin-2-yl)amino)carbonyl] benzenesulfonamide\} plus $0.2 \%$ v/v nonionic surfactant applied 14 to $21 \mathrm{~d}$ before the rating date (Dernoeden, 1990; Hutto et al., 2008; McCullough and Hart, 2008). Estimates of KBG cover were taken using a modification of the vertical point quadrant method (Gaussoin and Branham, 1989), where a 1.2 × 1.2-m frame was laid over the plots with an interval filament grid of 49 intersections. Rating dates were 3 Aug. ( \pm 4 d) in 2008, 2009, 2010, and 2011.
Treatments were arranged as a randomized complete block with four replications. Data were analyzed as a general linear model, which assumes homogeneous variance. Variance between years was found to be heterogeneous and, therefore, variances were fit separately for each year with PROC GLIMMIX in SAS (SAS Institute, Inc., Cary, NC) and data were combined over years for analysis of variance
(Little et al., 2006). Analysis of variance was determined in SAS and a mean separation was performed using Fisher's protected least significant difference at $P \leq 0.05$.

\section{Results and Discussion}

An experiment $\times$ treatment interaction occurred for turfgrass cover rated up to 6

Table 1. Percentage kentucky bluegrass and perennial ryegrass seeding mixtures by weight, seed number, and seeding rate to achieve 1.9 pure live seeds $/ \mathrm{cm}^{2}$.

\begin{tabular}{|c|c|c|c|c|c|c|}
\hline \multicolumn{4}{|c|}{ Mixture } & \multicolumn{3}{|c|}{ Seeding rate } \\
\hline $\mathrm{KBG}^{\mathrm{z}}$ & $\mathrm{PRG}^{\mathrm{y}}$ & $\mathrm{KBG}$ & PRG & $\mathrm{KBG}$ & PRG & Total \\
\hline \multicolumn{2}{|c|}{ Percent by weight } & \multicolumn{2}{|c|}{ Seed number/kg } & \multicolumn{3}{|c|}{$\mathrm{kg} \mathrm{seed} / \mathrm{ha}$} \\
\hline 100 & 0 & $2,806,623$ & 0 & 83 & 0 & 83 \\
\hline 90 & 10 & $2,525,961$ & 60,125 & 78 & 10 & 88 \\
\hline 80 & 20 & $2,245,299$ & 120,250 & 78 & 20 & 98 \\
\hline 70 & 30 & $1,964,636$ & 180,375 & 73 & 34 & 107 \\
\hline 50 & 50 & $1,403,312$ & 300,626 & 68 & 68 & 137 \\
\hline 0 & 100 & 0 & 601,251 & 0 & 376 & 376 \\
\hline
\end{tabular}

${ }^{\mathrm{z}} \mathrm{KBG}=$ kentucky bluegrass consisting of 25\% each 'Odyssey', 'Arcadia', 'Mercury', 'SR2100', and 'America'.

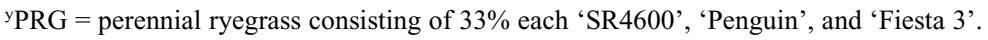

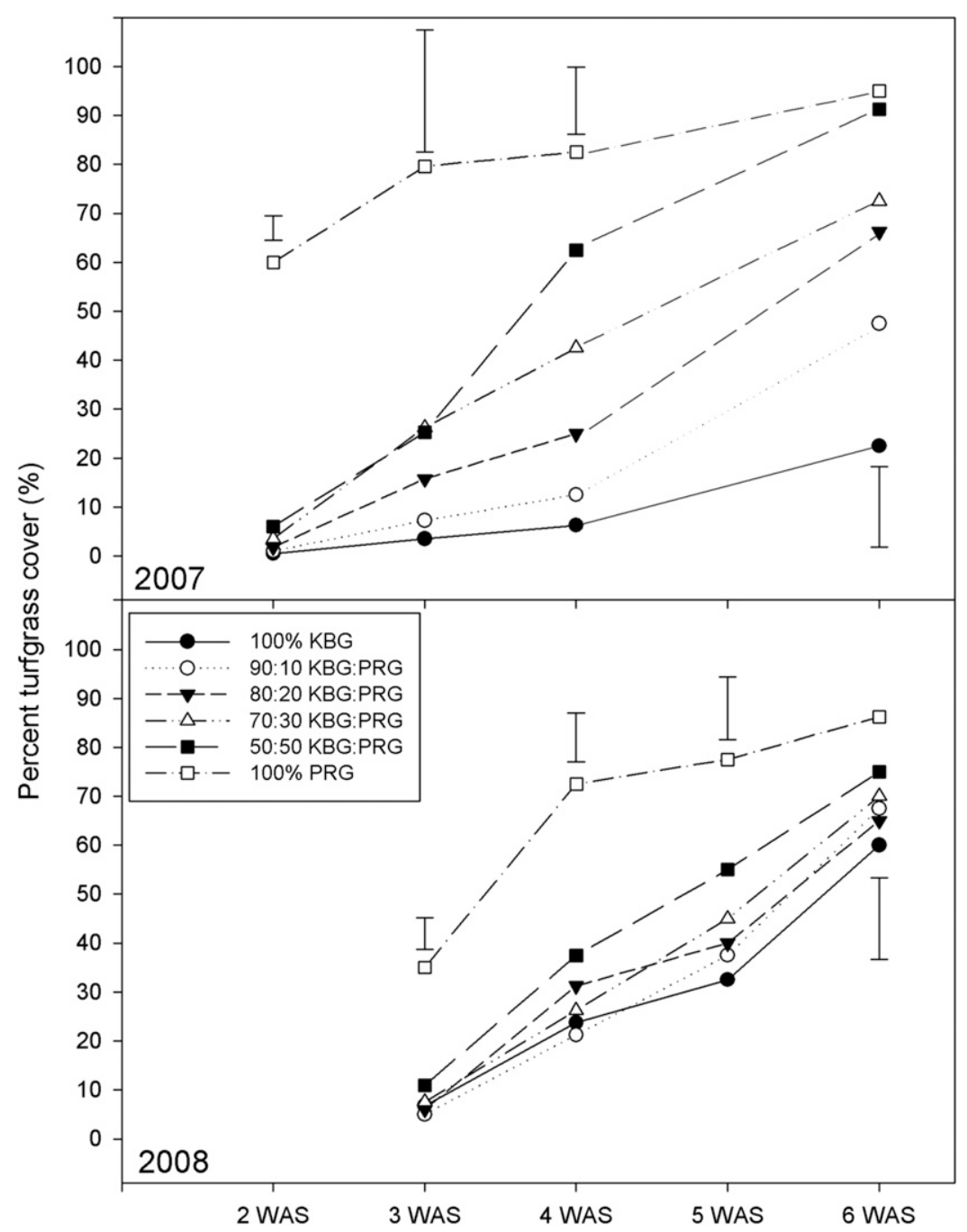

Fig. 1. Percent turfgrass cover for various kentucky bluegrass (KBG) and perennial ryegrass (PRG) mixtures seeded in 2007 and 2008 and rated through 6 weeks after seeding (WAS). Error bars represent Fisher's least significant difference (LSD) $(P \leq 0.05)$ within a rating period for comparison among treatments. Means are over four replications. 
WAS; therefore, treatment means are presented by year. An unusually warm fall in 2007 encouraged late crabgrass germination, which resulted in competition during establishment of the desired turf. Therefore, all treatments were slow to produce desirable turf cover, but especially mixtures higher in KBG. By October (10 WAS), weed cover ranged from $44 \%$ to $78 \%$ (data not shown). In 2007, 100\% PRG had the highest turfgrass cover at 2 and 3 WAS, whereas all other treatments produced lower but statistically similar turfgrass cover (Fig. 1). Turfgrass cover increased through 6 WAS for all treatments, and 100\% PRG and 50:50, 70: 30, and 80:20 KBG:PRG mixtures all produced equivalent cover at 6 WAS. In the more typical fall of 2008, turfgrass cover at 3 and 4 WAT was highest for $100 \%$ PRG, whereas all other treatments produced lower turf cover (Fig. 1). There were no differences in turf cover among the seed ratios at 6 WAS. October-rated (10 WAS) weed cover in 2008 was primarily annual bluegrass (Poa annua L.) and ranged from $1 \%$ in the $100 \%$ PRG treatment to $56 \%$ in the $100 \% \mathrm{KBG}$ treatment (data not shown). Unlike crabgrass, annual bluegrass began germinating well after the PRG and KBG and thus had less effect on turf cover during the first 6 weeks after seeding. By May after seeding in both years, all seed ratio treatments provided greater than $95 \%$ cover of desired turf (data not shown), thus increasing PRG in a KBG:PRG seed mixture affected cover only during the first fall after seeding under the conditions of this experiment.

Other factors have been shown to impact turf stand composition. Kentucky bluegrass seeded at $90 \mathrm{~kg} \cdot \mathrm{ha}^{-1}$ reduced weed cover compared with $\mathrm{KBG}$ seeded at $45 \mathrm{~kg} \cdot \mathrm{ha}^{-1}$ 2 months after seeding (Beard et al., 1980). Mowing 2 weeks after seeding at $1.3-\mathrm{cm}$ height favored KBG in a KBG:PRG mixture (Brede and Duich, 1984b). Our study indicates that initial turfgrass cover (up to 6 WAS) was favored by increasing amount of PRG in the seed mixture, especially for environments with unusually high weed pressure. Furthermore, seeding in the late summer usually limits pressure from summer annual weeds, like in 2008 , and greater than $50 \%$ PRG would be recommended in the KBG: PRG seed mixture to hasten cover compared with $100 \% \mathrm{KBG}$ for a typical late summer in Indiana.

No experiment $\times$ treatment interaction existed for KBG coverage rated in August 1 year or more after seeding; thus, data were averaged over experiments. One year after seeding, coverage of KBG was ranked from high to low according to the percentage of KBG in the original seed mixture. The $100 \%$ KBG and 90:10 KBG:PRG treatments produced the highest KBG cover 1 year after seeding (Fig. 2). By 3 years after seeding, all treatments containing KBG produced over $95 \%$ KBG cover. Although there were statistical differences between treatments, the range in $\mathrm{KBG}$ cover between the lowest and highest seeding ratios of KBG was only $2.3 \%$. The 2007-seeded treatments were evaluated for

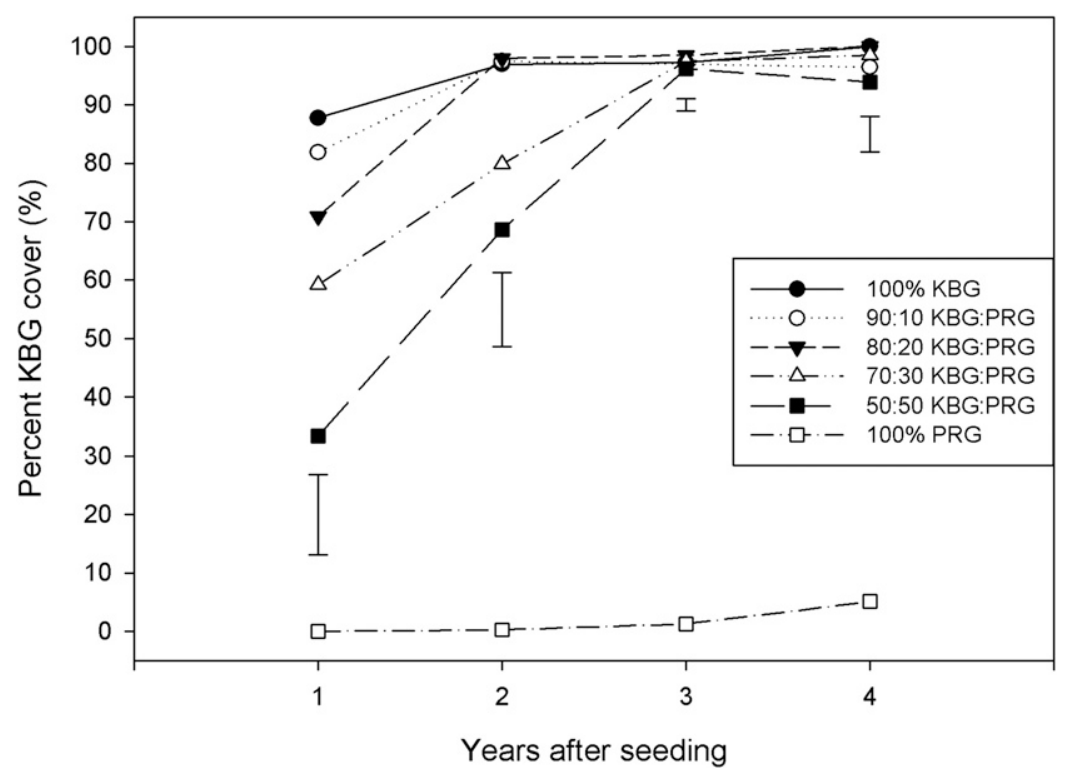

Fig. 2. August percent kentucky bluegrass (KBG) cover after seeding of various KBG and perennial ryegrass (PRG) mixtures. Cover was rated with the vertical point quadrant method after selective removal of PRG with chlorsulfuron. Means for the first 3 years are over two studies with four replications each and the fourth year means are over one study with four replications. Error bars represent Fisher's least significant difference (LSD) $(P \leq 0.05)$ within a rating period for comparison among treatments.

KBG cover in the fourth year after seeding and data were similar to those collected 3 years after seeding. With the exception of the $100 \%$ PRG treatment, all KBG:PRG seed mixtures tested shifted the turfgrass stand composition toward a dominant (greater than $95 \%$ ) KBG stand. Because chlorsulfuron causes a slow decline in PRG, it is possible that KBG expanded into voids left by declining PRG between application and rating date, thus inflating KBG percentages. However, there were only 3 weeks between application and rating and thus we would expect limited lateral spread of KBG into the voids.

Most KBG and PRG seed mixture ratios are recommended to achieve a 50:50 stand of KBG:PRG because this is simplistically proposed to be an ideal ratio for a mature turfgrass stand (Gibeault et al., 1980). Furthermore, the turf stand ratio of 50:50 KBG: PRG has been frequently targeted in research studies (Brede and Duich, 1984a, 1984b; Larsen et al., 2004; Larsen and Bibby, 2005; Stier et al., 2005). Similar to our study, Brede (1982) reported a stand initially dominated by PRG eventually shifted to a predominantly KBG stand. However, others have found a 90: 10 seed mixture of KBG:PRG was dominated by PRG after 4 years (Hsiang et al., 1997). Dunn et al. (2002) also reported a 90:10 KBG: PRG mixture was eventually dominated by PRG after 5 years. Furthermore, Hunt and Dunn (1993) found that all tested mixtures of KBG, tall fescue (Festuca arundinacea Schreb.), and PRG were dominated by PRG after 5 years, likely as a result of mowing heights $2.2 \mathrm{~cm}$ or less.

The ecology of a KBG:PRG stand can be complex and it is not always clear why some seed mixtures of KBG:PRG will shift toward a KBG-dominated stand and others shift toward PRG. One explanation is that KBG cultivars in the seed mixes with more aggressive or better-adapted traits dominate the other grasses, whereas less aggressive or poorly adapted KBG cultivars maintain equal populations of $\mathrm{KBG}$ with other grasses (Brede, 2005; Lickfeldt et al., 2002; Stier et al., 2005). A second explanation is studies that shifted toward a KBG-dominated stand were conducted in Indiana (current study) (Fig. 3) and Pennsylvania (Brede, 1982), where KBG may be favored in hotter, more humid summers with high disease pressure that would likely limit PRG more than KBG, depending on disease susceptibility of specific cultivars used. Conversely, in the Ontario study (Hsiang et al., 1997), plots shifted toward PRG where it is well adapted in cooler climates. Other climates with harsh winters could increase the long-term KBG: $\mathrm{PRG}$ ratio given the poor winter tolerance of PRG, but conditions favoring summer patch (Magnaporthe poae) or necrotic ringspot (Ophiosphaerella korrae) could favor PRG. Differences in wear tolerance between KBG and PRG could also account for variance in stand composition. Although PRG dominated mixed stands in the study in Missouri by Dunn et al. (2002), traffic was simulated and previous research on older PRG cultivars show greater wear tolerance than KBG (Shearman et al., 1974). Therefore, it is possible that the newer PRG cultivars tested by Dunn et al. (2002) also had greater wear tolerance than KBG; thus, traffic was more influential than climate, shifting the stand populations toward PRG. Stier et al. (2005) found in Wisconsin that the cultivar of KBG in a mixture with PRG influenced final stand composition when subjected to traffic and the seed mixture contained $50 \%$ or greater KBG. However, 


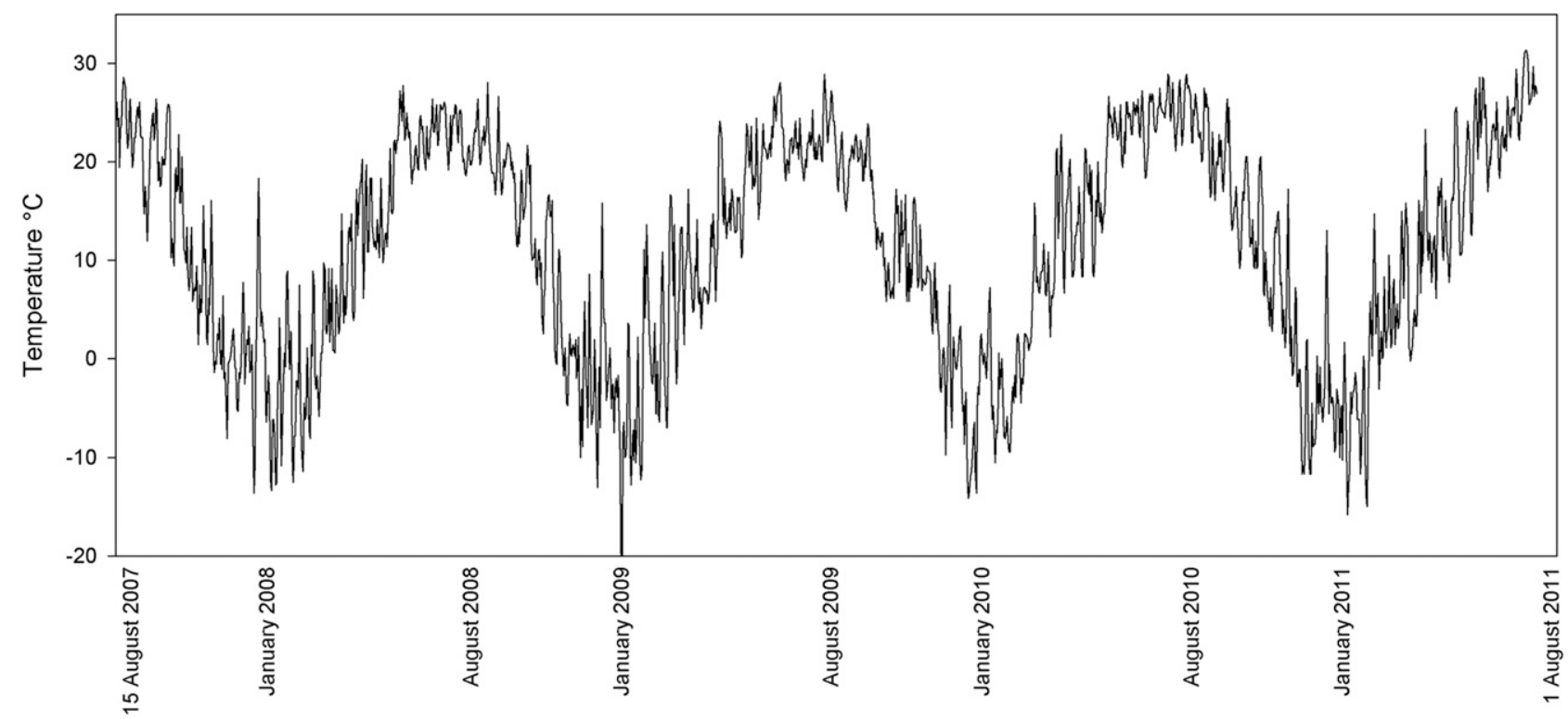

Fig. 3. Mean of daily high and low air temperatures at the W.H. Daniel Turfgrass Research and Diagnostic Center in West Lafayette, IN, for the duration of the kentucky bluegrass and perennial ryegrass seed mixture experiments.

PRG became the dominant species under traffic for seed mixtures with less than $50 \%$ KBG regardless of cultivar.

Timing of initial mowing after seeding and mowing height are also factors shown to influence the composition of a mixed turfgrass stand of KBG:PRG with close, early mowing favoring KBG (Brede and Duich, 1984b). In our study, initial mowing was conducted when $\approx 10 \%$ of leaf blades reached the mowing height of $6.35 \mathrm{~cm}$ and was mowed twice per week thereafter. Our study substantiates other reports in that the composition of a turf stand after seeding KBG within a mixture of KBG:PRG is the result of numerous ecological factors and difficult to generalize or predict across locations and environments. Beard gives a succinct synopsis of turf stand dynamics in his textbook, stating "The composition of a turfgrass community is generally in a constant state of change but the rate of change varies greatly depending on the age of the community as well as the environmental and cultural conditions to which it is exposed" (Beard, 1973).

Our study was located in Indiana, just north of the transition zone, where KBG outperforms PRG in heat and drought tolerance and tolerance to common summer diseases. Under the conditions of our study, increasing the proportion of PRG to KBG up to $50 \%$ by weight will expedite turfgrass cover to maximize customer satisfaction for lawn installers, but the KBG:PRG seeding ratio was important only during the fall of establishment, especially when weed pressure was high. One hundred percent PRG ( 0 : $100 \mathrm{KBG}: \mathrm{PRG}$ ) excluded, we found that all seed mixtures of KBG and PRG shifted to a predominantly (greater than 95\%) KBG stand after 3 years when maintained as a lawn. Therefore, KBG and PRG seed mixes up to $50 \%$ PRG by weight can be used when predicted weed pressure is high and still expect the lawn composition to be greater than $95 \%$ KBG after 3 years. Seeding 90:10 or 80:20 KBG:PRG (wt:wt) seed mixtures can provide speed of cover equivalent to 50 : 50 mixtures in areas or years with low weed pressure and will likely consist of greater than $95 \% \mathrm{KBG}$ within 2 years of establishment.

\section{Literature Cited}

Beard, J.B. 1973. Turfgrass: Science and culture. Prentice-Hall, Englewood Cliffs, NJ.

Beard, J.B., D.P. Martin, and F.B. Mercer. 1980 Investigation of net-sod production as a new technique, p. 353-360. In: Beard, J.B. (ed.). Proc. 3rd Intl. Turfgrass Res. Conf., Munich, West Germany, 11-13 July 1977. ASA, CSSA, SSSA, and Intl. Turfgrass Soc., Madison, WI.

Blaser, R.E., T. Taylor, W. Griffeth, and W. Skrdla. 1956. Seedling competition in establishing forage plants. Agron. J. 48:1-6.

Brede, A.D. 1982. Interaction of three turfgrass species. PhD. diss., Pennsylvania State University, University Park, PA.

Brede, A.D. 2005. Necrotic ring spot and turf quality as affected by kentucky bluegrass cultivar and species mixtures. Intl. Turfgrass Soc. Res. J. 10:156-162.

Brede, A.D. and J.M. Duich. 1984a. Establishment characteristics of kentucky bluegrass-perennial ryegrass turf mixtures as affected by seeding rate and ratio. Agron. J. 76:875-879.

Brede, A.D. and J.M. Duich. 1984b. Initial mowing of kentucky bluegrass-perennial ryegrass seedling turf mixtures. Agron. J. 76:711-714.

Christians, N.E. 2011. Fundamentals of turfgrass management. 4th Ed. John Wiley \& Sons, Inc., Hoboken, NJ.

Davis, R.R. 1958. The effect of other species and mowing on height on persistence of lawn grasses. Agron. J. 50:671-673.

Dernoeden, P.H. 1990. Comparison of three herbicides for selective tall fescue control in kentucky bluegrass. Agron. J. 82:278-282.

Dunn, J.H., E.H. Ervin, and B.S. Fresenburg. 2002. Turf performance of mixtures and blends of tall fescue, kentucky bluegrass, and perennial ryegrass. HortScience 37:214-217.

Gaussoin, R.E. and B.E. Branham. 1989. Influence of cultural factors on species dominance in a mixed stand of annual bluegrass/creeping bentgrass. Crop Sci. 29:480-484.

Gibeault, V.A., R. Autio, S. Spaulding, and V.B. Youngner. 1980. Mixing turfgrasses controls fusarium blight. Calif. Agr. 34:11-12.

Hsiang, T., K. Carey, B. He, and J.L. Eggens. 1997. Composition of mixtures of four turfgrass species four years after seeding under nonwear conditions. Intl. Turfgrass Soc. Res. J. 8:671-679.

Hunt, K.L. and J.H. Dunn. 1993. Compatibility of kentucky bluegrass and perennial ryegrass with tall fescue in transition zone turfgrass mixtures. Agron. J. 85:211-215.

Hutto, K.C., J.M. Taylor, and J.D. Byrd, Jr. 2008. Soil temperature as an indicator for perennial ryegrass control. Weed Technol. 22:245-248.

Larsen, S.O., C. Andreason, and P. Kristofferson. 2004. Differential sowing time of turfgrass species effects the establishment of mixtures. Crop Sci. 44:1315-1322.

Larsen, S.O. and B.M. Bibby. 2005. Difference in thermal time requirement for germination of three turfgrass species. Crop Sci. 45:20302037.

Lickfeldt, D.W., T.B. Voigt, and A.M. Hamblin. 2002. Composition and characteristics of blended kentucky bluegrass stands. HortScience 37:1124-1126.

Little, R., G. Milliken, W. Stroup, R. Wolfinger, and O. Schabenberger. 2006. SAS for mixed models. 2nd Ed. SAS Institute Inc., Cary, NC.

McCullough, P.E. and S.E. Hart. 2008. Roughstalk bluegrass and tall fescue control in Kentucky bluegrass with sulfosulfuron. Online. Applied Turfgrass Sci. doi: 10.1094/ATS-2008-062501 RS.

Shearman, R.C., J.B. Beard, C.M. Hansen, and R. Apaella. 1974. Turfgrass wear simulator for small plot investigations. Agron. J. 66:332-334.

Stier, J.C., J. Bae, and G. Jung. 2005. Composition of kentucky bluegrass and perennial ryegrass mixtures subjected to traffic. Intl. Turfgrass Res. Soc. J. 10:645-653.

Stier, J.C., E.J. Koeritz, and M. Garrison. 2008. Timing the establishment of kentucky bluegrass: Perennial ryegrass mixtures for football fields. HortScience 43:240-244. 